\title{
Exploring the potential of life-history key innovation: brook breeding in the radiation of the Malagasy treefrog genus Boophis
}

\author{
M. VENCES, *II F. ANDREONE,† F. GLAW, J. KOSUCH,§ A. MEYER,* H.-C. SCHAEFER§ and \\ M. VEITH§ \\ *Department of Biology (Evolutionary Biology), University of Konstanz, 78457 Konstanz, Germany, †Museo Regionale di Scienze \\ Naturali, Laboratory of Vertebrate Taxonomy and Ecology, Via G. Giolitti, 36, 10123 Torino, Italy, łZoologische Staatssammlung \\ München, Münchhausenstrasse 21, 81247 München, Germany, §Institut für Zoologie, Universität Mainz, Saarstraße 21, 55099 \\ Mainz, Germany
}

\begin{abstract}
The treefrog genus Boophis is one of the most species-rich endemic amphibian groups of Madagascar. It consists of species specialized to breeding in brooks (48 species) and ponds (10 species). We reconstructed the phylogeny of Boophis using 16S ribosomal DNA sequences $(558 \mathrm{bp})$ from 27 species. Brook-breeders were monophyletic and probably derived from an ancestral pond-breeding lineage. Pond-breeders were paraphyletic. The disparity in diversification among pond-breeders and brook-breeders was notable among endemic Malagasy frogs, although it was not significant when considering Boophis alone. Sibling species which have different advertisement calls but are virtually indistinguishable by morphology were common among brook-breeders; genetic divergence between these species was high (modal $8 \%$ total pairwise divergence). Substitution rates in brook-breeding species were significantly higher than in pond-breeders. Speciation of pond-breeders may be hindered by their usually more synchronous reproduction and a higher vagility which enhances gene flow, while a higher potential of spatial segregation and speciation may exist along brooks.
\end{abstract}

Keywords: Amphibia, Madagascar, Mantellidae, phylogeny, sibling species

Received 28 November 2001; revision received 18 April 2002; accepted 18 April 2002

\section{Introduction}

Adaptive radiations have received particular attention as sources of organismal diversity. One major topic has been the exploration of why some lineages gave rise to higher levels of diversity than others. As an explanation, the influence of key innovations has often been invoked (Sanderson \& Donoghue 1996). These have been defined as morphological, physiological, or behavioural traits that enable a lineage to colonize new adaptive zones and thereby confer the ability to undergo rapid speciation and diversification (Simpson 1953; Liem 1973).

Correspondence: Miguel Vences. IIPresent address: Institute of Biodiversity and Ecosystem Dynamics, Zoological Museum, University of Amsterdam, PO Box 94766, 1090 GT Amsterdam, the Netherlands; Fax: + 49 2219417284; E-mail: m.vences@t-online.de
Recent theoretical and empirical evidence suggests that rapid diversification processes may in part take place through sympatric rather than allopatric speciation. This process is triggered by ecological specialization (Dieckmann \& Doebeli 1999) or sexual selection (Higashi et al. 1999; Gavrilets 2000; Boughman 2001). The latter model highlights the importance of optical and other mate recognition mechanisms for speciation (Barraclough et al. 1995).

Treefrogs of the genus Boophis are one of the most spectacular radiations within the endemic Malagasy family Mantellidae (Bossuyt \& Milinkovitch 2000; Vences \& Glaw 2001). Taking into account recent descriptions, more than 40 nominal and about 18 undescribed Boophis species are attributed to seven phenetic species groups (BlommersSchlösser \& Blanc 1991; Glaw \& Vences 1994, 2000). Among anurans, the genus Boophis stands out for its large number of cryptic sibling species. By morphology alone these are 
virtually indistinguishable, and they are usually diagnosed only by their advertisement call or by differences in coloration (Blommers-Schlösser 1979; Glaw \& Vences 2000).

Speciation through call differentiation has been suggested for certain insect groups in which females recognize their mates by species-specific advertisement calls (Henry 1994). Similarly, in Boophis the bioacoustically divergent cryptic species may also be examples for this type of speciation. If this were the case, a low genetic differentiation among many Boophis species would be predicted, as was documented in other instances of incipient speciation (e.g. Meyer et al. 1990; Schliewen et al. 1994; Freeland \& Boag 1999; Wilson et al. 2000).

In this study, we sequenced fragments of the $16 \mathrm{~S}$ ribosomal RNA (rRNA) gene from 27 Boophis species to investigate their phylogenetic relationships, ages and rates of speciation among brook and pond-breeding species. We used the mitochondrial data to test the hypotheses of (i) low genetic divergence between sibling species and (ii) reproductive mode as possible key innovation and mechanism for diversification.

\section{Material and methods}

\section{DNA sequencing}

DNA was extracted using QIAmp tissue extraction kits (Qiagen) from muscle tissue samples preserved in pure ethanol. We used the primers 16SA-L (light chain; 5'-CGC CTG TTT ATC AAA AAC AT-3') and 16SB-H (heavy chain; 5'-CCG GTC TGA ACT CAG ATC ACG T-3') of Palumbi et al. (1991) to amplify a section [ca. 550 base pairs (bp)] of the mitochondrial $16 \mathrm{~S}$ ribosomal RNA gene. We chose this gene instead of a more variable marker, such as cytochrome $b$ or the control region, based on preliminary data which indicated a high amount of genetic divergence between Boophis species. Polymerase chain reaction (PCR) conditions followed Vences et al. (2000b). PCR products were purified using QIAquick purification kits (Qiagen) and were sequenced using an automatic DNA sequencer (ABI 377). Sequences (see Appendix I for GenBank accession numbers) were aligned using the computer program SEQUENCE NAVIGATOR 2.0 (Applied Biosystems), taking secondary structures into account (Kjer 1995). The alignment needed single gaps at four positions, double gaps at two positions, and three or four consecutive gaps at two additional positions. Of the latter two cases, one was due to insertions in only four species, while the second was within a hypervariable region of $53 \mathrm{bp}$ (positions $257-309$ of the alignment).

In addition to our own data we also re-analysed the five Boophis sequences from the work of Richards et al. (2000) who studied higher-level relationships in a more inclusive sample of Malagasy frogs.

\section{Phylogenetic analyses}

Phylogenetic analyses were carried out using PAUP*, version $4 b 8$ (Swofford 2001). Prior to phylogenetic reconstruction, we explored which substitution model fitted our sequence data the best. We applied a hierarchical likelihood method to test the goodness-of-fit of nested substitution models, using the program MODELTEST (Posada \& Crandall 1998). The substitution model estimated as best fitting our data (see Results) was used to obtain maximum likelihood (ML) trees using the heuristic search option, and a random additionsequence with 10 replicates. Maximum parsimony (MP) and neighbour-joining $(\mathrm{NJ})$ trees were also calculated.

In the MP analysis we conducted two heuristic searches, coding each gap (also in multiple gap sequences) either as fifth state or as missing character, with branch swapping using the tree bisection-reconnection (TBR) routine. To identify multiple islands of equally most parsimonious trees, 100 random addition-sequence replicates were performed. Only minimal-length trees were saved and zero-length branches were collapsed. In the $\mathrm{NJ}$ analyses we used LogDet distances, which are robust against possible variation of sequence evolution among lineages (Lockhart et al. 1994). All MP and $\mathrm{NJ}$ analyses were repeated after exclusion of the hypervariable region (53 bp).

All available Boophis sequences were included in a first data exploration. To avoid the masking of cladogenetic patterns in the tests of tree shape and in diversity comparisons by inclusion of multiple sequences of the same species, we conducted further analyses with a reduced data set of only a single sequence per species. The excluded sequences differed by a maximum of only three substitutions from the included sequences.

Two thousand bootstrap replicates (Felsenstein 1985) were run in all analyses except ML (only 100 bootstrap replicates due to computational constraints). The robustness of nodes was tested by Shimodaira-Hasegawa tests as implemented in PAUP*. Sequences were checked for clock-like behaviour using the program tREE-PUZZLE 5.0 (Schmidt et al. 2000).

Tests of relative molecular substitution rates (Takezaki et al. 1995) were conducted using PHYLTEST (Kumar 1996); of the different substitution models implemented in this program, we used Jukes-Cantor distances, uncorrected $P$-distances of transversion only, Kimura two-parameter distances, and Kimura two-parameter distances of transversions only.

\section{Tests of diversification rate and tree imbalance}

Although disparities in species numbers among lineages may seem obvious, the differences are not significant in many cases. Under a Markovian model of cladogenesis a stochastic difference in initial rates can lead to a much higher diversity in one of the lineages (Slowinski \& Guyer 1989). Careful 
examination of the initial data is therefore needed to assess possible differences in species diversity (Sanderson \& Donoghue 1996). Our approach largely follows Cook \& Lessa (1998) who applied a number of different statistics to a similar problem (the assumed high rates of diversification in subterranean rodents). Standard null model tests (Slowinski \& Guyer 1989, 1993) were used to compare standing diversity in brook-breeding and pond-breeding Boophis. The more sensitive three-taxon tests, as implemented in LRDIVERSE (Sanderson \& Donoghue 1994; Sanderson \& Wojciechowski 1996), were performed with 1000 Monte Carlo replicates, keeping the relative age of the internal node as unknown.

We used the Colless index (Colless 1982) and confidence intervals as provided by Kirkpatrick \& Slatkin (1993) as a measure of tree imbalance. This index was calculated by hand from the topology of the ML tree. The program END-EPI (Rambaut et al. 1997) was used to estimate relative cladogenesis. This statistic calculates the probability of the existence of a given number of tips (terminal taxa) of a lineage through time in comparison with the actual number of tips, and identifies branches with higher than expected rates of cladogenesis (Nee et al. 1996). As a basis for calculation of relative cladogenesis (see below) we built a tree using the nonparametric rate-smoothing algorithm in the $\mathrm{R} 8 \mathrm{~s}$ program
(Sanderson 1997). POWELL algorithm was chosen and the unit for branch lengths was defined as per site.

\section{Results}

\section{Phylogeny and substitution rates}

In the preliminary data exploration using all 37 available Boophis sequences and three outgroups, and coding gaps as fifth state, of 558 characters included in the analysis, 328 were constant, 44 were variable but parsimony-uninformative, and 186 were parsimony-informative. MODELTEST suggested a general time-reversible substitution model with a gamma distribution shape parameter of 0.713 , a proportion of invariable sites of 0.498 and empirical base frequencies (A: 0.341; C: 0.207; G: 0.196; T: 0.256) and substitution rates (A-C, 3.65; A-G, 17.030; A-T, 7.938; C-G, 2.380; C-T, 39.395; $\mathrm{G}-\mathrm{T}, 1.000)$. These settings were used for ML analyses.

In the ML tree (Fig. 1), with the exception of the Boophis majori group, pairs and trios of sibling species were grouped as monophyletic units. Species assigned to the same phenetic species group formed monophyletic groups in some cases (B. goudoti group; B. luteus group) but appeared to be paraphyletic in several other instances (B. majori group; $B$. rappiodes group; $B$. tephraeomystax group). The included

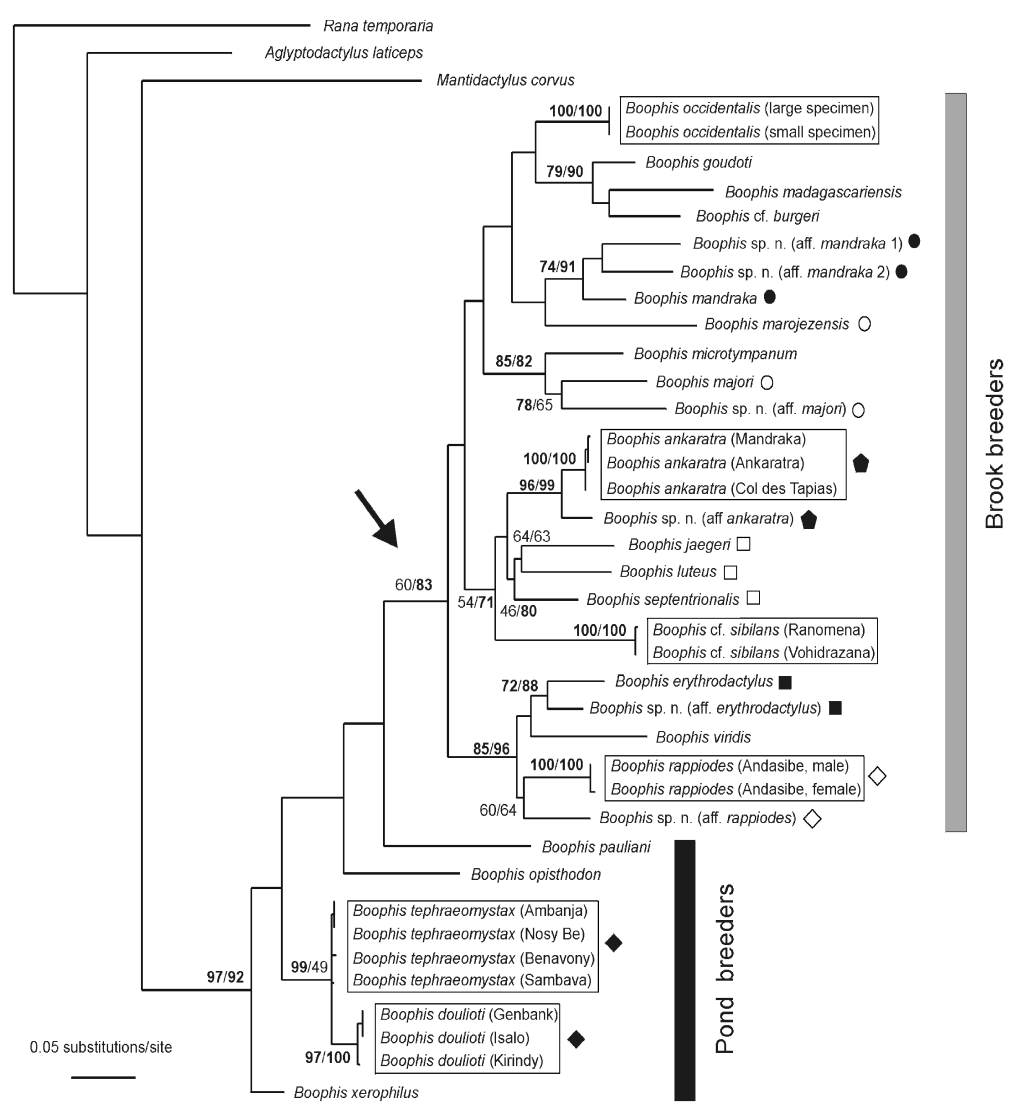

Fig. 1 Maximum likelihood phylogram based on all available sequences of the 16S rRNA gene (558 bp). Rana temporaria was used as outgroup. Numbers are bootstrap values in per cent (2000 replications) for MP and NJ analyses, respectively. No values are given for nodes which received support below $50 \%$ in both analyses. Values above $70 \%$ are printed in bold. The arrow marks the support for monophyly of the brook-breeding clade. Different symbols mark pairs or trios of sibling species which are not or are almost not distinguishable morphologically after preservation (Table 1). Sequences of conspecific specimens are included in boxes. 
Table 1 Classification of pairs and trios of sibling species (not or almost not distinguishable morphologically after preservation) included in the present study relative to their distribution pattern and bioacoustic differences

\begin{tabular}{|c|c|c|c|}
\hline $\begin{array}{l}\text { Allopatric species with } \\
\text { weak call differences }\end{array}$ & $\begin{array}{l}\text { Altitudinally separated } \\
\text { species with weak call } \\
\text { differences }\end{array}$ & $\begin{array}{l}\text { (Potentially) syntopic } \\
\text { species with strong } \\
\text { call differences }\end{array}$ & $\begin{array}{l}\text { Allopatric species with } \\
\text { strong call differences }\end{array}$ \\
\hline B. luteus & B. ankaratra & B. marojezensis & B. jaegeri \\
\hline -B.septentrionalis & $-B$. aff. ankaratra & $\begin{array}{l}\text { - B. majori } \\
- \text { B. aff. majori }\end{array}$ & -B. luteus \\
\hline B. tephraeomystax & & B. erythrodactylus & B. jaegeri \\
\hline- B. doulioti & & $\begin{array}{l}\text { - B. aff. erythrodactylus } \\
\text { B. rappiodes } \\
- \text { B. aff. rappiodes } \\
\text { B. mandraka } \\
- \text { B. aff. mandraka } 1^{*} \\
\text { - B. aff. mandraka } 2^{*}\end{array}$ & - B. septentrionalis \\
\hline
\end{tabular}

*B. mandraka 1 and 2 refer to two undescribed species which both are morphologically similar to B. mandraka.

brook-breeding Boophis were grouped in one clade, whereas the pond-breeding species were arranged paraphyletically at the basis of the cladogram. Sequences from specimens which a priori were considered to be conspecific were grouped with high bootstrap support as monophyletic units in all cases except for B. tephraeomystax.

These results were also confirmed by the different NJ and MP analyses performed.

(i) NJ, both with all characters and after exclusion of the hypervariable region, supported the same patterns outlined above; bootstrap values for the analysis including all characters are given in Fig. 1, those after exclusion of the hypervariable sites did not show relevant differences.

(ii) MP, with gaps coded as fifth state and all characters included, yielded 12 equally most parsimonious trees [1042 steps, consistency index (CI) 0.378, retention index (RI) 0.610]; these were not unequivocal regarding brookbreeder monophyly, since a second alternative, placing basally a clade containing Boophis rappiodes, B. viridis and B. erythrodactylus was also equally parsimonious. However, the bootstrap value $(60 \%)$ and a majority rule consensus tree $(67 \%)$ did support monophyly of brook-breeding Boophis. Excluding the hypervariable region did not alter these results; 333 equally most parsimonious trees were obtained (684 steps; CI 0.393, RI 0.627). Brook-breeder monophyly was not apparent from a strict consensus tree but from a majority rule tree $(85 \%)$ and from the bootstrap analysis (65\%). The monophyly of the included species of the B. luteus group and B. goudoti group and paraphyly of the $B$. rappiodes group, $B$. majori group and B. tephraeomystax group, and the sister-group relationships of sibling species, were confirmed by each of the analyses.

(iii) MP, with gaps coded as missing data and including all characters, yielded 28 equally most parsimonious trees (993 steps; CI 0.363, RI 0.605). These did not unambiguously support brook-breeder monophyly, but in a $50 \%$ majority consensus tree brook-breeding Boophis were monophyletic (79\%). The same was true in a bootstrap analysis (59\%). Exclusion of the hypervariable region resulted in 200 equally most parsimonious trees (657 steps, CI 0.385, RI 0.627). In a strict consensus of these the brook-breeding species did form a monophyletic group, which received a bootstrap value of $79 \%$. Monophyly/paraphyly of Boophis species groups and relationships of sibling species were as in the former analyses.

In the reduced set of 27 Boophis sequences (one sequence per species), coding gaps as fifth character and not including the hypervariable region, 328 out of 558 characters were constant, 54 were variable but parsimony-uninformative, and 176 were parsimony-informative. The topology of the ML tree as shown in Fig. 2 totally agreed with the results of the preliminary data exploration. As in the previous analyses, all MP and NJ searches (with hypervariable region included or excluded) agreed upon the monophyly/paraphyly of the different Boophis species groups. Monophyly of brook-breeding species was supported by the NJ trees, MP and NJ bootstrap analyses (68-69\%), and MP 50\% majority rule consensus trees, while the MP strict consensus trees were equivocal in this respect.

The sequences of Richards et al. (2000) included four species of brook-breeding Boophis (B. albilabris, B. erythrodactylus, B. luteus, B. madagascariensis) and one pond-breeder (B. doulioti, as B. tephraeomystax). Re-analysis of these sequences using Aglyptodactylus as outgroup (results not shown) yielded bootstrap supports of 74\%, 85\% and 73\% (ML, MP, $\mathrm{NJ}$ ) for the monophyly of a group composed by the four brook-breeders.

A tree obtained enforcing a molecular clock with TREEPUZZLE was rejected on a significance level of $P<0.05$ by a likelihood ratio test when compared with the ML tree. Tests 


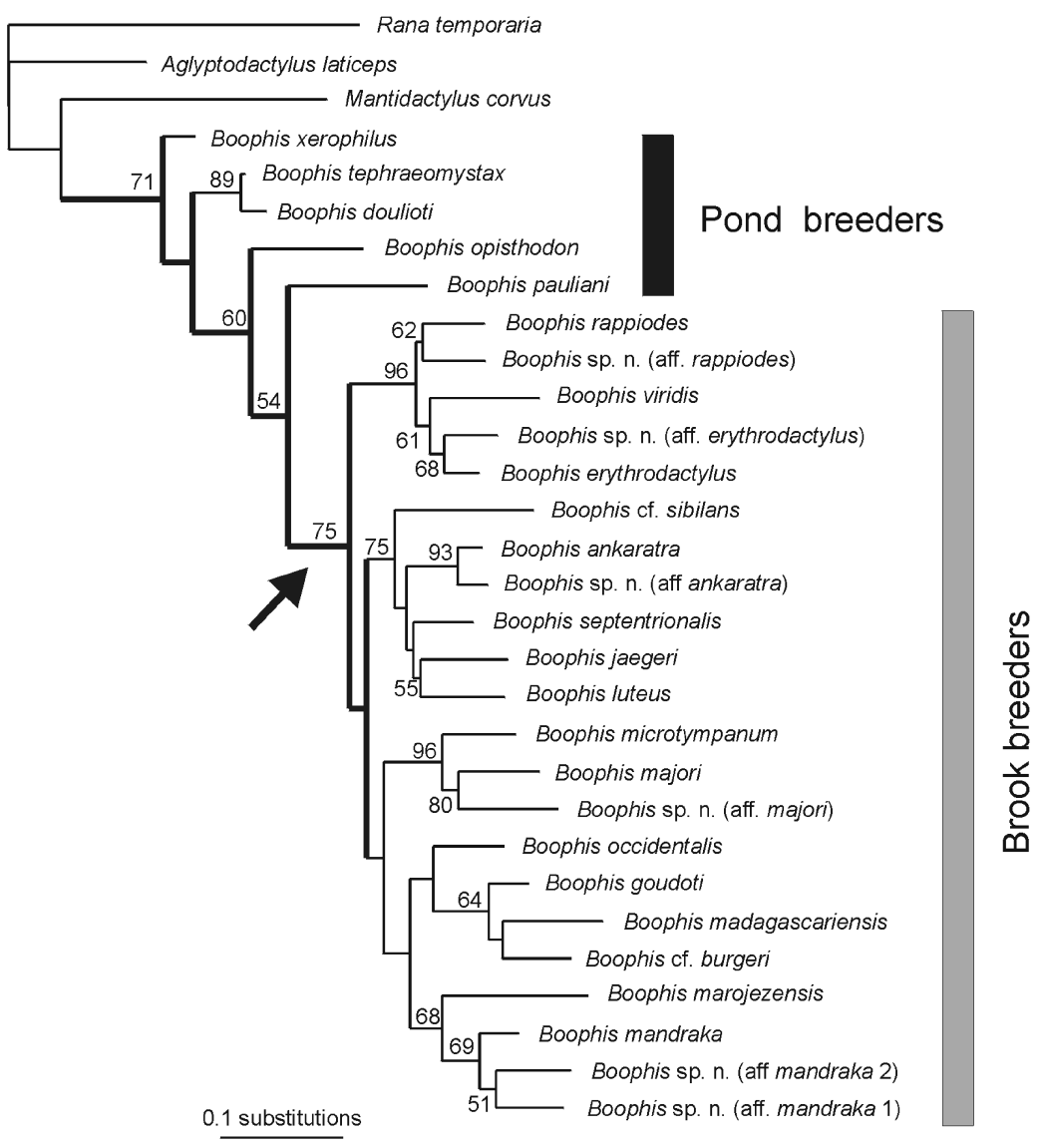

Fig. 2 Maximum likelihood phylogram of analysis of a reduced data set (one sequence per species only). Numbers are bootstrap values in per cent (100 replications). Thicker lines indicate lineages that were found to have statistically higher than expected rates of cladogenesis $(P<0.01)$ after nonparametric rate smoothing of the tree. The arrow marks the support for monophyly of the brook-breeding clade.

of relative nucleotide substitution rates using PHYLTEST significantly rejected rate constancy when comparing the brook-breeding lineage separately with each pond-breeder. This result was obtained independently from the substitution model used, except for a single comparison considering transversions only. In all cases the branch lengths of brookbreeders were longer, indicating a faster substitution rate. The results were similar when comparing the pond-breeding B. doulioti with the four brook-breeders of the data set of Richards et al. (2000), but in these analyses the comparisons based on transversions only did not yield significant differences.

\section{Diversification rates}

Three taxon tests with the program LRDIVERSE, using the ML tree topology (Fig. 2), indicated a significantly higher speciation rate in brook-breeders. For instance, using the pond-breeders closest to the brook-breeding lineage (Boophis opisthodon as outgroup, B. pauliani as first ingroup and the brook-breeders as second ingroup - species diversities 1, 1 and 22), only the model assuming different speciation rates of the brook-breeding lineage received $P$-values smaller than 0.98 and was therefore selected $(P<0.005)$.

However, the nonmonophyly of pond-breeders was only weakly indicated by the phylogenetic results, and a more conservative approach assuming their monophyly was therefore also used. This LRDIVERSE analysis did not indicate significant differences in speciation rate between pondbreeding and brook-breeding Boophis when the respective standing diversities were compared and Aglyptodactylus (with three species) was used as outgroup ( $P$-value for null model $=0.863$ ). Such a conservative assumption was also used for tests of standing diversity (Table 2). These did not provide evidence for an increased diversification of brookbreeding Boophis. Cumulative tests also failed to indicate such a pattern when the second large group of Malagasy frogs with brook specialists, the mantellines, were included in a combined analysis (Table 2).

The Colless index of the ML tree (0.391) was above the high cut-off for the corresponding confidence interval (Kirkpatrick \& Slatkin 1993) and thus demonstrated a significant tree asymmetry.

Analysis of the clock-like ML tree with END-EPI (Rambaut et al. 1997) showed significantly higher than expected rates of cladogenesis at almost all basal positions of the tree, starting with the split between the outgroup and Boophis, and including the origin of the main brook-breeding lineages (not shown). The same pattern was found after application of nonparametric rate smoothing using the R8s program (Fig. 2). 
Table 2 Species diversity in Malagasy anurans and $P$-values for two-taxon tests of imbalance (Slowinski \& Guyer 1989, 1993) and the cumulative test (Slowinski \& Guyer 1993) across pairs of taxa

\begin{tabular}{|c|c|c|c|}
\hline & Pond-breeding & Brook-breeding & $P$-value \\
\hline \multicolumn{4}{|l|}{ Mantellidae } \\
\hline Boophinae (Boophis) & 10 & 48 & 0.175 \\
\hline Laliostominae (Aglyptodactylus + Laliostoma) & 4 & 0 & - \\
\hline Mantellinae A (Mantidactylus + Mantella)*† & 20 & 38 & 0.351 \\
\hline Mantellinae B (Mantidactylus + Mantella)* & 27 & 50 & 0.355 \\
\hline \multicolumn{4}{|l|}{ Hyperoliidae } \\
\hline Hyperoliinae (Heterixalus) & 10 & 0 & - \\
\hline \multicolumn{4}{|l|}{ Microhylidae§ } \\
\hline Scaphiophryninae & 9 & 0 & - \\
\hline Dyscophinae & 3 & 0 & - \\
\hline \multicolumn{4}{|l|}{ Cumulative tests } \\
\hline Boophinae + Mantellinae A & & & 0.234 \\
\hline Boophinae + Mantellinae B & & & 0.235 \\
\hline
\end{tabular}

The phylogenetic basis of the groupings is mainly based on Richards et al. (2000). Following the NJ tree presented by these authors, the subgenus Spinomantis (represented in the phylogeny by Mantidactylus aglavei) is here considered as part of the brook-breeding lineage, and brook-breeding mantellines are considered as a monophyletic group. The species numbers are recent estimates (e.g. Glaw \& Vences 2000) that include nominal species and already identified but not yet formally described species (F. Glaw and M. Vences, personal observation).

*A few deviating species (brook-breeders in the pond-breeding lineage) were excluded: Mantella cowani group, Mantidactylus grandisonae. tTree-hole or phytotelmic-breeders in the pond-lineage excluded; all species from the brook-lineage which probably have no freeswimming tadpoles excluded.

$\ddagger$ Tree-hole and phytotelmic-breeders included in the pond lineage; species without free-swimming tadpoles but which regularly reproduce along brooks included in the brook-lineage.

§Microhylids of the subfamily Cophylinae are not regarded here; this endemic and speciose radiation (about 50 identified species) has nonfeeding tadpoles and reproduces in terrestrial nests or tree-holes.

An overall comparison of the native frog fauna in Madagascar (Table 2) showed that only two out of six subfamilies include brook-breeding lineages. For one of these, the Boophinae (genus Boophis), our data indicated monophyly of brook-breeders as opposed to pond-breeders. The second group including both reproductive strategies, the subfamily Mantellinae (sensu Vences \& Glaw 2001), also appears to be divided into two main lineages that largely correspond to brook and pond breeders (Richards et al. 2000; Vences et al. 2002a). If vicariance scenarios apply to explain the origin of Malagasy anurans (Bossuyt \& Milinkovitch 2001), each anuran group was present on Madagascar since its separation from Gondwana and should have undergone a similar biogeographic history. A direct comparison of brook-breeding and pond-breeding lineages may therefore be justified and supports a significantly higher diversity of pond-breeders as compared with brook-breeding lineages (Mann-Whitney $U$-test; $P<0.05$ ).

\section{Levels of divergence}

We assessed levels of divergence using two models: pairwise total sequence divergence in per cent (Fig. 3), which allows for a direct comparison with values in other animal groups (e.g. Avise et al. 1998), and pairwise ML distances, which better account for the specific substitution model in our data set. We calculated divergences (i) between Boophis and other mantellid genera (Mantidactylus and Aglyptodactylus), (ii) between pond- and brook-breeding Boophis, (iii) between brook-breeding species groups, and (iv) within species groups. In the ML distance calculations the mean intergeneric values were distinctly higher than the intrageneric Boophis values $(0.42$ vs. $0.28,0.22$ and 0.17$)$. This trend was less distinct in the total divergence calculations (16\% vs. $13 \%, 12 \%$ and $10 \%$; Fig. 3), probably indicating the start of saturation. Total divergences below 9\% were always found between species a priori assigned to the same phenetic species group. Most of these (and all below 6\%) referred to species pairs considered as sibling species. Divergences between sibling species ranged from 2 to $13 \%$, with a modal value of $8 \%$. Species with strong differences in advertisement calls (whether syntopic, potentially syntopic, or allopatric) had divergences of $5-13 \%$. The two identified divergences lower than $5 \%$ referred to allopatrically separated species pairs with weak call differences $(B$. aff. ankaratraB. ankaratra; B. tephraeomystax-B. doulioti). Conspecific specimens consistently showed a very low degree of sequence differentiation ( $0-3$ substitutions; $0-0.5 \%$ divergence). 


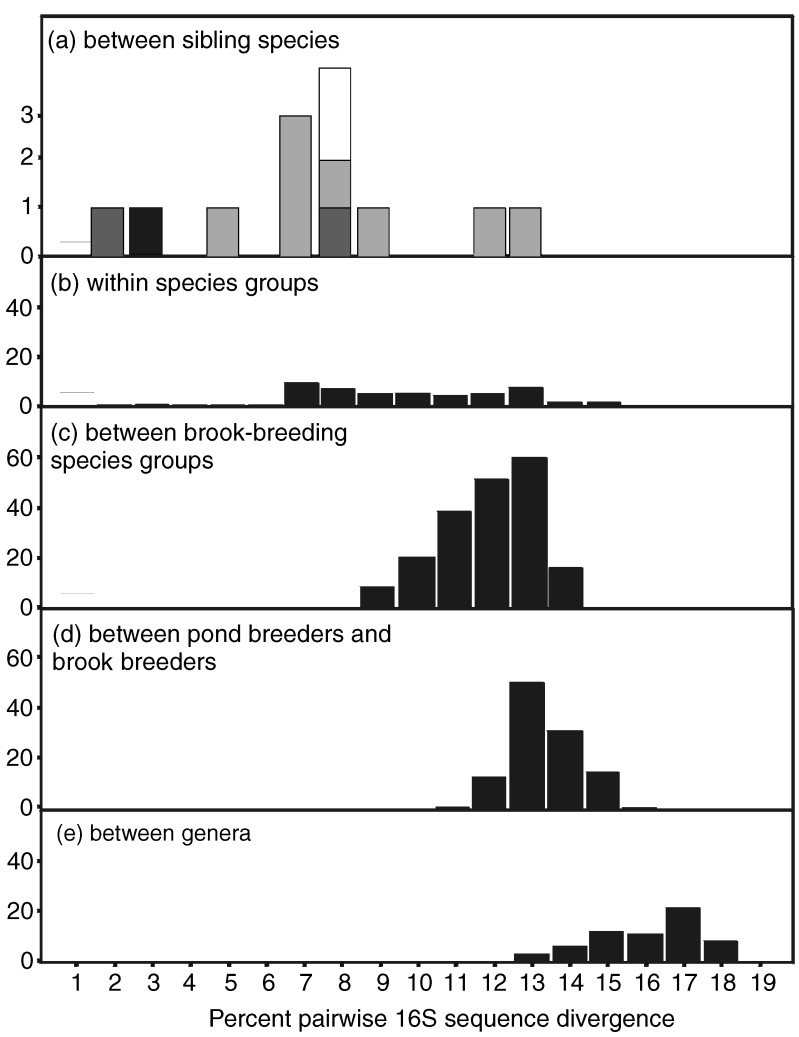

Fig. 3 Distribution of pairwise total divergences in per cent among $558 \mathrm{bp}$ fragments of the $16 \mathrm{~S}$ rRNA gene: (a) between different types of Boophis sibling species (as listed in Table 2): white bars, latitudinally separated species with strong call differentiation; black bars, latitudinally separated species with weak call differentiation; dark grey bars, altitudinally differentiated species with weak call differentiation; light grey bars, syntopic species with strong call differentiation; (b) between brook-breeding Boophis included in the same species group (the sibling pairs are a subset of these data); (c) between brook-breeding Boophis included in different species groups; (d) between species of the brook-breeding lineage and the pond-breeding assemblage in Boophis; and (e) between species of Boophis and outgroup species of Mantidactylus and Aglyptodactylus. Based on the reduced data set (one sequence per species).

\section{Discussion}

\section{Monophyly and diversity of brook-breeding Boophis}

The present study provides moderate support (bootstrap values $60-83 \%$ ) for the monophyly of the assemblage of brook-breeding frogs of the genus Boophis. Similar values were found by re-analysis of the sequences from Richards et al. (2000) in a reduced taxon set (73-85\%). Although Shimodaira-Hasegawa (SH) tests could not exclude significantly all alternative topologies (results not shown), we consider the monophyly of brook-breeders as relatively well established since it agrees with two relevant osteological characters: (i) representatives of all brook-breeding species groups lack the anterolateral hyoid process which is present in the pond-breeding B. tephraeomystax and $B$. doulioti; and (ii) all brook-breeders are characterized by the apomorphic state of two tarsal elements while there are three at least in one pond-breeder (B. doulioti) (Vences et al. 2002a).

Our sample of species (five pond-breeders vs. 22 brookbreeders; $19 \%$ vs. $81 \%$; including taxa from all phenetic species groups) was representative of the overall species diversity so far identified in Boophis (Table 2; $17 \%$ vs. $83 \%$ ). As our sample included representatives of all species groups we suppose that our phylogenetic conclusions can also be extended to the remaining species.

Four pond-breeders (B. opisthodon, B. doulioti, B. tephraeomystax, B. xerophilus) are known to occur at least partly outside densely forested areas; at least the latter three occur outside rainforest. In the brook-breeding lineage, only $B$. goudoti lives outside forested areas in the Malagasy highlands (Blommers-Schlösser 1979) and B. laurenti, B. microtympanum and $B$. williamsi are specialized to montane heathlands (Glaw \& Vences 1994). A few other species, such as $B$. luteus, are also regularly found in largely degraded areas. The percentage of forest species (which depend at least on stretches of continuous gallery forest) is thus below $70 \%$ among pond-breeders and about $90 \%$ among brook-breeders, indicating a possible association of brookbreeding with rainforest habitat.

\section{High levels of divergence between siblings}

We herein provide the first survey of genetic divergence in a representative sample of pairs of sibling species in Malagasy frogs. The high genetic divergence observed between most species pairs contrasts with the low intraspecific variation. In six species in which more than one specimen was examined (B. ankaratra, B. occidentalis, B. rappiodes, B. cf. sibilans, $B$. tephraeomystax, $B$. doulioti), divergence between sequences did not amount to more than $0.5 \%$ (three substitutions). The modal divergence of $8 \%$ between sibling species was much higher than would be expected in the case of recent Pleistocene-Holocene speciation events (Klicka \& Zink 1997; Avise et al. 1998). We did not identify a single example of a very recently diverged pair of sibling species which differ by advertisement call. Instead, all syntopic species with important bioacoustic differentiation had high sequence divergences, and the lowest levels of divergence were found between allopatric species. Our data therefore do not provide evidence for a recent rapid sympatric speciation by sexual selection in Boophis. If the same factors influencing Boophis speciation have been active over the evolutionary history of the genus, our data would rather favour allopatric speciation as a prevailing mechanism in this group, as it is assumed for tropical salamanders (García-Paris et al. 2000). 


\section{Patterns of diversification in Boophis}

Using the molecular phylogeny of Boophis as the basis, the three taxon test supports a significant disparity in diversification rates between brook- and pond-breeding Boophis. Also, the ML tree (Fig. 2) was found to be significantly asymmetric.

In contrast, other analyses led to less unequivocal results. Higher than expected rates of cladogenesis were found in the initial radiation of brook-breeding Boophis, but also characterized all other basal splits in the genus, including pond-breeding species. This was true when enforcing a clock-like tree, but also after nonparametric rate smoothing which has been shown to provide more accurate estimates of divergence times in the case of nonclock-like substitution rates (Sanderson 1997).

Despite the obvious differences between species numbers of brook-breeding and pond-breeding Boophis species, the comparisons of standing diversities were not significant in a conservative approach that assumed monophyly of pond-breeders as an alternative hypothesis. The crucial point is the supposed paraphyly of pond-breeders, a question which cannot be unequivocally solved with the present data.

Future analyses of larger data sets are needed to understand the relevance of the indications of a higher diversification rate of brook-breeding Boophis compared to pond-breeders. The tendencies of an overall higher species diversity of brook-breeding clades among Malagasy frogs, however, appear to correlate with a lower mitochondrial nucleotide substitution rate in two pond-breeding lineages: Boophis and the microhylid genus Scaphiophryne (Vences et al. 2002b). Reproduction in ponds is usual in open savannah landscapes in which permanent brooks are less frequent. Lentic waters are often temporary, and a highly synchronous 'explosive' breeding behaviour is therefore shown by pond-breeding Boophis in arid environments (Andreone et al. in press). Furthermore, savannah-breeders are also vagile since ponds may form at different sites each year. Such natural history patterns contribute to a high degree of gene flow within and between populations. This may prevent sympatric and allopatric speciation and fixation of mutations, thereby causing a lower species diversity and slower substitution rates in pond-breeders.

Slowinski \& Guyer (1993) explicitly distinguish between intrinsic causes of diversity (i.e. morphological novelties that can be seen as key innovations) and extrinsic causes (i.e. environmental changes or tectonic activity). If brookbreeding adaptations were partly responsible for Boophis diversity, they certainly could be defined as key innovations. The fact that four out of six lineages of Malagasy frogs did not colonize brooks indicates that important modifications of mating and egg-laying behaviour as well as embryonal and larval development are necessary for an original pondbreeder to reproduce successfully in brooks. However, brookbreeding has also an extrinsic aspect. Occurrence of small permanent brooks in Madagascar is closely related to rainforests. Furthermore, most Malagasy rainforests are on relatively steep slopes where few lentic waters occur. It is plausible to assume that rainforests were a novelty for the ancestors of the extant Malagasy amphibian fauna: In vicariance scenarios (Duellman \& Trueb 1986; Bossuyt \& Milinkovitch 2001) ancestral mantellids were present on Madagascar already in the Early Cretaceous when probably a rather seasonal and partly xeric climate prevailed (Spicer et al. 1994). In dispersal scenarios (Krause et al. 1997) they reached the Malagasy west coast in the Cenozoic from Africa via waif dispersal, and had to be adapted to aridity to survive under the conditions encountered (Vences et al. 2000a). Hence, the wealth of new ecological niches in rainforest opened up for these ancestral frogs, and only some of them succeeded in colonizing this new habitat. Those which switched to reproduction in brooks rather than ponds were relieved of the need of synchronous breeding. Temporal and spatial segregation of subpopulations reduced effective population sizes and favoured fixation of mutations, thereby accelerating DNA substitution rates and probably promoting speciation.

\section{Acknowledgements}

We are grateful to Nirhy Rabibisoa, Domoina Rakotomalala, Olivier Ramilison, Noromalala Raminosoa, Fara Ranaivojaona, Jasmin Randrianirina and Denis Vallan for their help in the field. Michael J. Sanderson provided crucial software. We are also indebted to the Malagasy authorities for research and export permits. The work of F.G. and M.V. was made possible by a cooperation accord between the Département de Biologie Animale, Université d'Antananarivo and the Zoologische Staatssammlung München; that of F.A. by a cooperation accord between the Parc Botanique et Zoologique de Tsimbazaza, Antananarivo, and the Museo Regionale di Scienze Naturali, Torino. Financial support was granted by the Deutscher Akademischer Austauschdienst (DAAD) and the Deutsche Forschungsgemeinschaft (BO 682/5-1 and VE 247/1-2).

\section{References}

Andreone F, Vences M, Guarino FM, Glaw F, Randrianirina J (2002) Natural history and larval morphology of Boophis occidentalis (Anura: Mantellidae: Boophinae) provide new insights into the phylogeny and adaptive radiation of endemic Malagasy frogs. Journal of Zoology, London, in press.

Avise JC, Walker D, Johns GC (1998) Speciation duration and Pleistocene effects on vertebrate phylogeography. Proceedings of the Royal Society of London B, 265, 1707-1712.

Barraclough TG, Harvey PH, Nee S (1995) Sexual selection and taxonomic diversity in passerine birds. Proceedings of the Royal Society of London B, 259, 211-215.

Blommers-Schlösser RMA (1979) Biosystematics of the Malagasy frogs. II. The genus Boophis (Rhacophoridae). Bijdragen Tot de Dierkunde, 49, 261-312.

Blommers-Schlösser RMA, Blanc CP (1991) Amphibiens (première partie). Faune de Madagascar, 75, 1-379.

Bossuyt F, Milinkovitch MC (2000) Convergent adaptive radiations 
in Madagascan and Asian ranid frogs reveal covariation between larval and adult traits. Proceedings of the National Academy of Sciences of the USA, 97, 6585-6590.

Bossuyt F, Milinkovitch MC (2001) Amphibians as indicators of Early Tertiary 'Out-of-India' dispersal of vertebrates. Science, 292, 93-95.

Boughman JW (2001) Divergent sexual selection enhances reproductive isolation in sticklebacks. Nature, 411, 944-948.

Colless DH (1982) Phylogenetics: the theory and practice of phylogenetic systematics II [book review]. Systematic Zoology, 31, 100-104.

Cook JA, Lessa EP (1998) Are rates of diversification in subterranean South American tuco-tucos (genus Ctenomys, Rodentia: Octodontidae) unusually high? Evolution, 52, 1521-1527.

Dieckmann U, Doebeli M (1999) On the origin of species by sympatric speciation. Nature, 400, 354-357.

Duellman WE, Trueb L (1986) Biology of Amphibians. McGraw-Hill, New York

Felsenstein J (1985) Confidence limits on phylogenies: an approach using the bootstrap. Evolution, 39, 783-791.

Freeland JR, Boag PT (1999) The mitochondrial and nuclear genetic homogeneity of the phenotypically diverse Darwin's ground finches. Evolution, 53, 1553-1563.

García-Paris M, Good DA, Parra-Olea G, Wake DB (2000) Biodiversity of Costa Rican salamanders: implications of high levels of genetic differentiation and phylogeographic structure for species formation. Proceedings of the National Academy of Sciences of the USA, 97, 1640-1647.

Gavrilets S (2000) Rapid evolution of reproductive barriers driven by sexual conflict. Nature, 403, 886-889.

Glaw F, Vences M (1994) A Fieldguide to the Amphibians and Reptiles of Madagascar, 2nd edn, including Mammals and Freshwater Fish. Vences and Glaw, Köln.

Glaw F, Vences M (2000) Current counts of species diversity and endemism of Malagasy amphibians and reptiles. In: Diversité et Endémisme de Madagascar (eds Lourenço WR, Goodman SM), pp. 243-248. Mémoires de la Société de Biogéographie, Paris.

Henry CS (1994) Singing and cryptic speciation in insects. Trends in Ecology and Evolution, 9, 388-392.

Higashi M, Takimoto G, Yamamura N (1999) Sympatric speciation by sexual selection. Nature, 402, 523-626.

Kirkpatrick M, Slatkin M (1993) Searching for evolutionary patterns in the shape of a phylogenetic tree. Evolution, 47, 1171-1181.

Kjer KM (1995) Use of rRNA secondary structure in phylogenetic studies to identify homologous positions: an example of alignment and data presentation from the frogs. Molecular Phylogenetics and Evolution, 4, 314-330.

Klicka J, Zink RM (1997) The importance of recent Ice Ages in speciation: a failed paradigm. Science, 277, 1666-1669.

Krause DW, Hartman JH, Wells NA (1997) Late Cretaceous vertebrates from Madagascar. Implications for biotic changes in deep time. In: Natural Change and Human Impact in Madagascar (eds Goodman SM, Patterson BD), pp. 3-43. Smithsonian Institution Press, Washington and London.

Kumar S (1996) PHYLTEST: Phylogeny Hypothesis Testing Software. The Pennsylvania State University, Pennsylvania.

Liem KF (1973) Evolutionary strategies and morphological innovations: cichlid pharyngeal jaws. Systematic Zoology, 22, 425-441.

Lockhart PJ, Steel MA, Hendy MD, Penny D (1994) Recovering evolutionary trees under a more realistic model of sequence evolution. Molecular Biology and Evolution, 11, 605-612.
Meyer A, Kocher TD, Basasibwaki P, Wilson AC (1990) Monophyletic origin of Lake Victoria cichlid fishes suggested by mitochondrial DNA sequences. Nature, 347, 550-553.

Nee S, Barraclough TG, Harvey PH (1996) Temporal changes in biodiversity: detecting patterns and identifying causes. In: Biodiversity: a Biology of Numbers and Difference (ed. Gaston K), pp. 230-252. Blackwell Science, London.

Palumbi SR, Martin A, Romano S, McMillan WO, Stice L, Grabowski G (1991) The Simple Fool's Guide to PCR, Version 2.0. Privately published document compiled by S. Palumbi, Dept. Zoology, University of Hawaii, Honolulu.

Posada D, Crandall KA (1998) Modeltest: testing the model of DNA substitution. Bioinformatics, 14, 817-818.

Rambaut A, Harvey PH, Nee S (1997) End-Epi: an application for reconstructing phylogenetic and population processes from molecular sequences. Computational Applied Bioscience, 13, 303-306.

Richards CM, Nussbaum RA, Raxworthy CJ (2000) Phylogenetic relationships within the Madagascan boophids and mantellids as elucidated by mitochondrial ribosomal genes. African Journal of Herpetology, 49, 23-32.

Sanderson MJ (1997) A nonparametric approach to estimating divergence times in the absence of rate constancy. Molecular Biology and Evolution, 14, 1218-1231.

Sanderson MJ, Donoghue MJ (1994) Shifts in diversification rate with the origin of angiosperms. Science, 264, 1590-1593.

Sanderson MJ, Donoghue MJ (1996) Reconstructing shifts in diversification rates on phylogenetic trees. Trends in Ecology and Evolution, 11, 15-20.

Sanderson MJ, Wojciechowski MF (1996) Diversification rates in a temperate legume clade: are there 'so many species' of Astragalus (Fabaceae)? American Journal of Botany, 83, 1488-1502.

Schliewen UK, Tautz D, Pääbo S (1994) Sympatric speciation suggested by monophyly of crater lake cichlids. Nature, 368, 629-632.

Schmidt HA, Strimmer K, Vingron M, von Haeseler A (2000) TREEPUZZLE, Version 5.0. München.

Simpson GG (1953) The Major Features of Evolution. Columbia University Press, New York.

Slowinski JB, Guyer C (1989) Testing the stochasticity of patterns of organismal diversity: an improved null model. American Naturalist, 134, 907-921.

Slowinski JB, Guyer C (1993) Testing whether certain traits have caused amplified diversification: an improved method based on a model of random speciation and extinction. American Naturalist, 142, 1019-1024.

Spicer RA, Rees P, McA, Chapman JL (1994) Cretaceous phytogeography and climate signals. In: Palaeoclimates and Their Modelling. With Special Reference to the Mesozoic Era (eds Allen JRL, Hoskins BJ, Sellwood BW, Spicer RA, Valdes PJ), pp. 69-78. Chapman \& Hall, London.

Swofford DL (2001) PAUP*. Phylogenetic Analysis Using Parsimony (*And Other Methods), Version 4b8. Sinauer Associates, Sunderland, MA.

Takezaki N, Rzhetsky A, Nei M (1995) Phylogenetic test of the molecular clock and linearized trees. Molecular Biology and Evolution, 12, 823-833.

Vences M, Glaw F (2001) When molecules claim for taxonomic changes: new proposals on the classification of Old World treefrogs. Spixiana, 24, 85-92.

Vences M, Glaw F, Kosuch J, Das I, Veith M (2000a) Polyphyly of Tomopterna (Amphibia: Ranidae) based on sequences of the 
mitochondrial $16 \mathrm{~S}$ and $12 \mathrm{~S}$ rRNA genes, and ecological biogeography of Malagasy relict amphibian groups. In: Diversité et Endémisme de Madagascar (eds Lourenço WR, Goodman SM), pp. 229-242. Mémoires de la Société de Biogéographie, Paris.

Vences M, Kosuch J, Lötters S, Widmer A, Jungfer KH, Köhler J, Veith M (2000b) Phylogeny and classification of poison frogs (Amphibia: Dendrobatidae), based on mitochondrial 16S and 12S ribosomal RNA gene sequences. Molecular Phylogenetics and Evolution, 15, 34-40.

Vences M, Glaw F, Andreone F, Jesu R, Schimmenti G (2002a) Systematic revision of the enigmatic Malagasy broad-headed frogs (Laurentomantis Dubois, 1980), and their phylogenetic position in the endemic mantellid radiation of Madagascar. Contributions to Zoology, 70, 191-212.

Vences M, Aprea G, Capriglione T, Andreone F, Odierna G (2002b) Ancient tetraploidy and slow molecular evolution in Scaphiophryne: ecological correlates of speciation mode in Malagasy relict amphibians. Chromosome Research, 10, 127-136.

Wilson AB, Noack-Kunnmann K, Meyer A (2000) Incipient speciation in sympatric Nicaraguan crater lake cichlid fishes: sexual selection versus ecological diversification. Proceedings of the Royal Society of London B, 267, 2133-2141.

This work is part of a long-term study of the diversity and biogeography of the amphibians and other vertebrates of Madagascar. Miguel Vences is head of the vertebrate section of the Zoological Museum, University of Amsterdam and assistant professor; until April 2002 he was a postdoctoral fellow of the Deutsche Forschungsgemeinschaft in the laboratory of Axel Meyer at the University of Konstanz, using molecular methods to contribute to the understanding of speciation mechanisms in frogs. While his taxonomic and ecological work on the Malagasy herpetofauna is largely carried out in cooperation with Frank Glaw and Franco Andreone, a part of the molecular work has so far been performed in the laboratory of Michael Veith at the University of Mainz, in cooperation with Joachim Kosuch and Hans-Christian Schaefer. 


\section{Appendix I}

Specimens examined and GenBank accession numbers of sequences. All localities are in Madagascar except that of Rana temporaria (Germany)

\begin{tabular}{|c|c|c|c|c|}
\hline Species group & Species & Origin & Voucher & Genbank accession \\
\hline- & Rana (Rana) temporaria & Koblenz & ZFMK 69883 & AF124135 \\
\hline- & Aglyptodactylus laticeps & Kirindy & ZFMK 64135 & AF215329 \\
\hline- & Mantidactylus corvus & Isalo & ZFMK 70494 & AF215320 \\
\hline \multirow[t]{9}{*}{ luteus group } & Boophis ankaratra & Mandraka & ZSM 400/2000 & AJ315909 \\
\hline & Boophis ankaratra & Manjakatompo & ZSM 367/2000 & AJ315911 \\
\hline & Boophis ankaratra & Col des Tapias & ZSM 399/2000 & AJ315910 \\
\hline & Boophis sp. $n$. (aff. ankaratra) & Ranomafana & ZFMK 62907 & AJ315912 \\
\hline & Boophis jaegeri & Berara & ZSM 413/2000 & AJ315914 \\
\hline & Boophis luteus & Andasibe & UADBA 2000.063 & AJ315916 \\
\hline & Boophis septentrionalis & Ambre & ZSM 493/2000 & AJ315915 \\
\hline & Boophis cf. sibilans & Ranomena & ZFMK 62797 & AF215338 \\
\hline & Boophis cf. sibilans & Vohidrazana & ZSM 327/2000 & AJ315913 \\
\hline \multirow[t]{3}{*}{ goudoti group } & Boophis cf. burgeri & Marojejy & ZFMK 59905 & AF215336 \\
\hline & Boophis goudoti & Col des Tapias & not preserved & AJ315917 \\
\hline & Boophis madagascariensis & An'Ala & ZFMK 62265 & AF215337 \\
\hline microtympanum group & Boophis microtympanum & Col des Tapias & ZSM 393/2000 & AJ315918 \\
\hline \multirow[t]{2}{*}{ albilabris group } & Boophis occidentalis (large) & Berara & MRSN A2000 & AJ314820 \\
\hline & Boophis occidentalis (small) & Berara & MRSN uncat. & AJ314819 \\
\hline \multirow[t]{3}{*}{ majori group } & Boophis majori & Vohiparara & ZFMK 62672 & AF215340 \\
\hline & Boophis sp. n. (aff. majori) & Andasibe & ZSM 313/2000 & AJ315922 \\
\hline & Boophis marojezensis & Vohidrazana & ZSM 326/2000 & AJ315923 \\
\hline \multirow[t]{9}{*}{ rappiodes group } & Boophis erythrodactylus & Mandraka & ZSM 324/2000 & AJ314814 \\
\hline & Boophis sp. $n$. (aff. erythrodactylus) & Andasibe & ZFMK 62888 & AF215339 \\
\hline & Boophis mandraka & Mandraka & ZSM 346/2000 & AJ315921 \\
\hline & Boophis sp. $n$. (aff. mandraka 1) & Vohidrazana & ZSM 310/2000 & AJ315919 \\
\hline & Boophis sp. n. (aff. mandraka 2) & Ambavaniasy & NMBE 1046008 & AJ315920 \\
\hline & Boophis rappiodes (male) & Andasibe & ZSM $347 / 2000$ & AJ314815 \\
\hline & Boophis rappiode (female) & Andasibe & UADBA 2000.59 & AJ314816 \\
\hline & Boophis sp. $n$. (aff. rappiodes) & Andasibe & ZSM 344/2000 & AJ314817 \\
\hline & Boophis viridis & Andasibe & ZSM 338/2000 & AJ314818 \\
\hline \multirow[t]{9}{*}{ tephraeomystax group } & Boophis doulioti* & unknown* & USNM 59146 & AF026360 \\
\hline & Boophis doulioti & Isalo & ZFMK 70495 & AF215332 \\
\hline & Boophis doulioti & Kirindy & ZFMK 66690 & AF215334 \\
\hline & Boophis opisthodon & Cap Est & ZFMK 70480 & AF215331 \\
\hline & Boophis pauliani & Andasibe & ZSM 345/2000 & AJ315924 \\
\hline & Boophis tephraeomystax & Ambanja & ZSM 489/2000 & AJ312115 \\
\hline & Boophis tephraeomystax & Nosy Be & ZSM 458/2000 & AJ312114 \\
\hline & Boophis tephraeomystax & Cap Est & ZFMK 66685 & AF215333 \\
\hline & Boophis tephraeomystax & Sambava & UADBA 2000.379 & AJ312116 \\
\hline Boophis xerophilus & Kirindy & ZFMK 66705 & AF215335 & \\
\hline
\end{tabular}

Collection abbreviations are: MRSN, Museo Regionale di Scienze Naturali, Torino; NMBE, Naturhistorisches Museum Bern; UADBA, Université d'Antananarivo, Département de Biologie Animale (numbers are provisional field numbers of F. Glaw and M. Vences); USNM, United States National Museum; ZFMK, Zoologisches Forschungsinstitut und Museum A. Koenig, Bonn; ZSM, Zoologische

Staatssammlung, München.

*The B. doulioti sequence marked with a star was obtained from GenBank (published by Richards et al. 2000). 